\title{
Growth, Optical and Dielectric Studies on Pure and L-Lysine Doped KDP Crystals
}

\author{
N. Kanagathara ${ }^{1}$ and G. Anbalagan ${ }^{2}$ \\ ${ }^{1}$ Department of Physics, Vel Tech Multi Tech Dr. Rangarajan Dr. Sakunthala Engineering College, Avadi, Chennai 62, India \\ ${ }^{2}$ Department of Physics, Presidency College, Chennai 5, India
}

Correspondence should be addressed to N. Kanagathara, kanagathaara@gmail.com

Received 31 October 2011; Accepted 15 December 2011

Academic Editor: Mirosław A. Karpierz

Copyright (C) 2012 N. Kanagathara and G. Anbalagan. This is an open access article distributed under the Creative Commons Attribution License, which permits unrestricted use, distribution, and reproduction in any medium, provided the original work is properly cited.

\begin{abstract}
Optically good quality single crystals of pure and L-lysine monohydrochloride-doped KDP crystals have been grown by a slow evaporation method. The grown crystals have been subjected to optical and dielectric studies. The UV-Vis spectrum shows the transmitting ability of the crystals in the entire visible region and transmittance percentage is increased for the doped KDP crystals. From the dielectric study, it is found that the dielectric constant and the dielectric loss of L-lysine-doped KDP crystals were lower than the pure KDP crystals. Hence L-lysine-doped KDP crystals are found to be more beneficial from an application point of view as compared to pure KDP crystals.
\end{abstract}

\section{Introduction}

Materials with large optical nonlinearity are needed to realize applications in optoelectronics, telecommunication industries, laser technology, and optical storage devices.

ADP and KDP are two of the oldest crystals grown in large size for many applications and continue to be interesting materials both academically and industrially. Potassium dihydrogen phosphate (KDP) is an excellent inorganic nonlinear optical (NLO) material and has a considerable interest amongst several research workers because of its wide frequency, high efficiency of frequency conversion, and high damage threshold against high power laser. With the aim of improving the SHG efficiency of KDP, researchers have attempted to modify KDP crystals either by doping different type of impurities or by changing the growth conditions [19]. Most of amino acids possess NLO property; therefore, it is of interest to dope them in KDP crystals. The effects of amino acid on the NLO efficiency of KDP crystals were already published [1-3]. L-Lysine monohydrochloride dihydrate is a potential material to produce semiorganic crystals for nonlinear optical applications [3]. Also L-Lysine monohydrochloride dihydrate can be used as novel elastoeletro-optical materials $[4,5]$. In the present study, L-Lysine monohydrochloride amino-acid-doped KDP crystals were grown by slow aqueous solvent evaporation technique. The optical and dielectric behavior of the both pure and lysinedoped KDP crystals has been studied and discussed in detail.

\section{Experimental Procedure}

Commercially available KDP was used for the growth. Without any further purification, KDP was dissolved in double distilled water. After obtaining the saturation, the solution was stirred well for just two hours, filtered and kept separately for the slow evaporation. Similar procedure followed for the addition of $0.2 \%$ of L-Lysine monohydrochloride to the saturated solution of KDP. Within 12 days, transparent crystals of both pure $(11.98 \mathrm{~mm} * 5.96 \mathrm{~mm} * 3.34 \mathrm{~mm})$ and Lysine-doped KDP $(15.90 \mathrm{~mm} * 12.89 \mathrm{~mm} * 6.08 \mathrm{~mm})$ crystals were produced.

\section{Characterization}

The grown crystals have been subjected to UV-Vis and dielectric study. The UV-Visible spectrum of the grown pure and doped KDP crystal was recorded between 200-2500 nm 


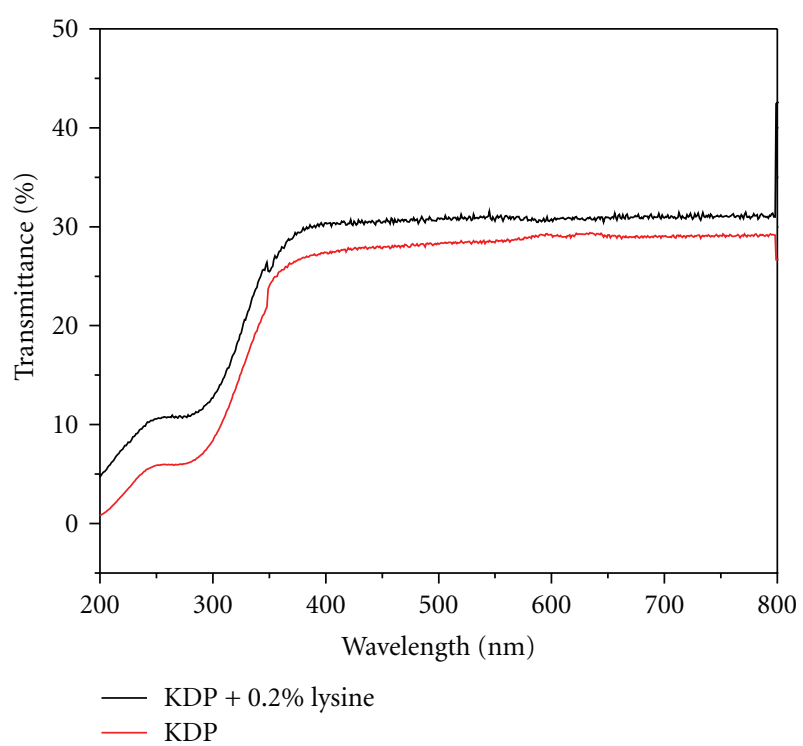

FIGURE 1: UV-Vis spectrum of pure and doped KDP crystals.

with high resolution using CARY/5E/UV Spectrophotometer covering the entire UV-Vis and near infrared region. The grown crystals were subjected to dielectric studies using a HIOKI model 3532-50 LCR HITESTER with a conventional two-terminal sample holder. The sample was electrode on either side with air-dying silver paste so that it behaves like parallel capacitor. The studies were carried from $353 \mathrm{~K}-473 \mathrm{~K}$ for frequency varying from $50 \mathrm{~Hz}$ to $5 \mathrm{MHz}$.

\section{Results and Discussion}

4.1. Optical Studies. Figure 1 shows the UV-Vis spectrum of both pure and doped KDP crystals. For optical applications, the crystal should be highly transparent in the considerable region of wavelength [10]. The good transmission of the crystal in the entire visible region suggests its suitability for second harmonic generation devices [11]. The UV-Visible spectral analysis shows that both the crystals are transparent in the entire visible region. There is strong absorption near the wave length of $277 \mathrm{~nm}$, which is slightly shifted to higher wavelength side from pure KDP and it may be assigned to electronic excitation in the L-Lysine-doped KDP crystal. The absence of absorption and excellent transmission in entire visible region makes this crystal a good candidate for optoelectronic application [9-11].

4.2. Dielectric Studies. The dielectric analysis is an important characteristic that can be used to fetch knowledge based on the electrical properties of a material medium as a function of temperature and frequency. Based on this analysis, the capability of storing electric charges by the material and capability of transferring the electric charge can be assessed.

Dielectric properties are correlated with electrooptic property of the crystals: particularly when they are nonconducting materials [12]. Microelectronics industry needs low dielectric constant $(\varepsilon r)$ materials as an interlayer dielectric [13].

The dielectric constant is calculated using the formula

$$
\varepsilon^{\prime}=\frac{C t}{\varepsilon_{0} A},
$$

where $C$ is capacitance $(\mathrm{F}), t$ the thickness $(\mathrm{m}), A$ the area $\left(\mathrm{m}^{2}\right)$, and $\varepsilon_{0}$ the absolute permittivity in the free space having a value of $8.854 * 10^{-12} \mathrm{Fm}^{-1}$.

Figures 2(a), 2(b), 3(a) and 3(b) show the variation of dielectric constant and dielectric loss with respect to frequency for all temperatures for both pure and lysinedoped KDP crystals.

From Figures 2(a) and 3(a), it is clear that dielectric constant increases with the increase in temperature for both pure and lysine-doped KDP crystals. Compared to the pure $\mathrm{KDP}$, dielectric constant $\left(\varepsilon_{r}\right)$ value is found to be low for doped KDP. A similar case appeared for pure and urea-doped KDP single crystals [14].

From Figures 2(b) and 3(b), it is clear that dielectric loss is high at low frequency and decreases with high frequencies. The low dielectric loss at high frequency reveals the high optical quality of the crystal with lesser defects, which is a desirable property of NLO applications $[15,16]$.

From Figures 4(a), 4(b), 5(a) and 5(b), It is found that the values of dielectric constant and dielectric loss increase with an increase in temperature and decrease with the increasing frequency. This may be due to the contributions of all the four polarizations such as electronic, ionic, orientation, and space charge, which are predominant in the lower frequency region [17]. The larger value of dielectric constant and dielectric loss at low frequency arises due to the presence of space charge polarization near the grain boundary interfaces, which depends on the purity and perfection of the sample [18]. The frequency dependence of dielectric constant $\varepsilon^{\prime}$ at different temperature shows that at high frequencies the dielectric constant values are almost temperature invariant but as the frequency decreases the dielectric constant value becomes more temperature sensitive. But at low frequencies, the dielectric constant is high for $473 \mathrm{~K}$ and low for $353 \mathrm{~K}$. At low frequencies, the dipoles can easily switch alignment with the changing field. As the frequency increases, the dipoles are less able to rotate and maintain phase with the applied filed, thus they reduce their contribution to the polarization.

Figures 6(a), 7(a) and 6(b), 7(b) give the variation in resistivity and conductivity with the frequency for the pure and lysine-doped KDP crystals. The a.c resistivity and a.c conductivity were calculated using the following relation:

$$
P=\frac{A}{2 \pi f C d}, \quad \sigma_{\rho}=\frac{1}{\rho},
$$

where $C$ is the capacitance, $d$ is the thickness, $A$ is the area of the crystal, and $f$ is the frequency of the applied field. As shown in Figures 6(a) and 7(a), a.c resistivity decreased rapidly as frequency increased. Obviously reverse trend was observed for a.c conductivity (Figures 6(b) and 7(b)) of the grown crystals [19].

Pyroelectricity is the ability of certain materials (polar materials) to generate temporary voltage when they are 

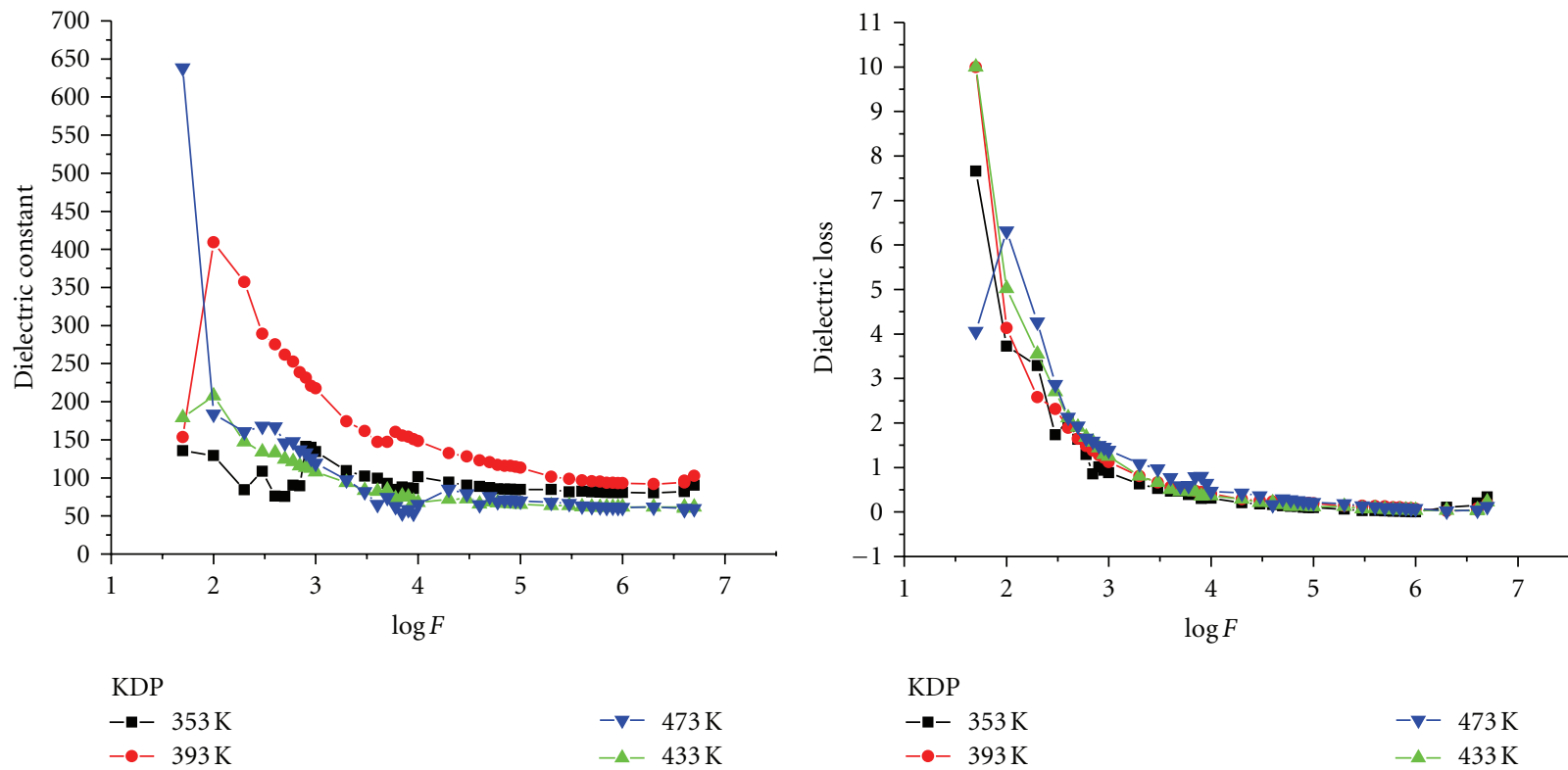

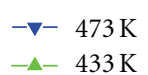

(a)

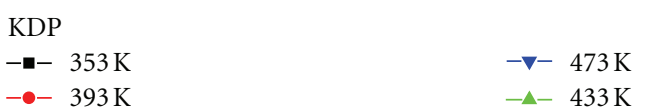

(b)

FIGURE 2: (a) Variation of dielectric constant with frequency for all temperatures (pure KDP). (b) Variation of dielectric loss with frequency for all temperatures (lysine-doped KDP).

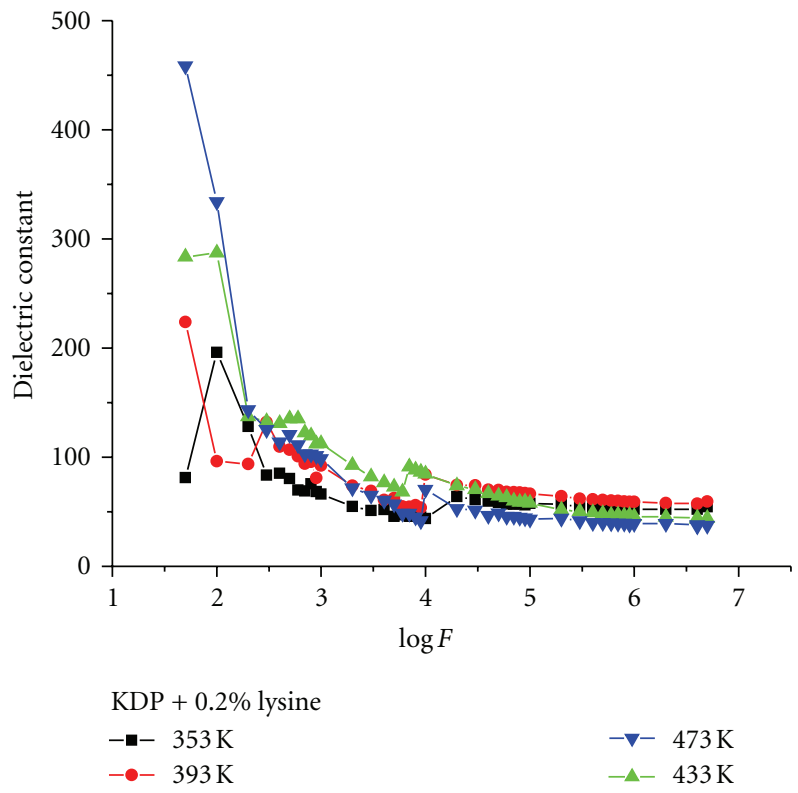

(a)

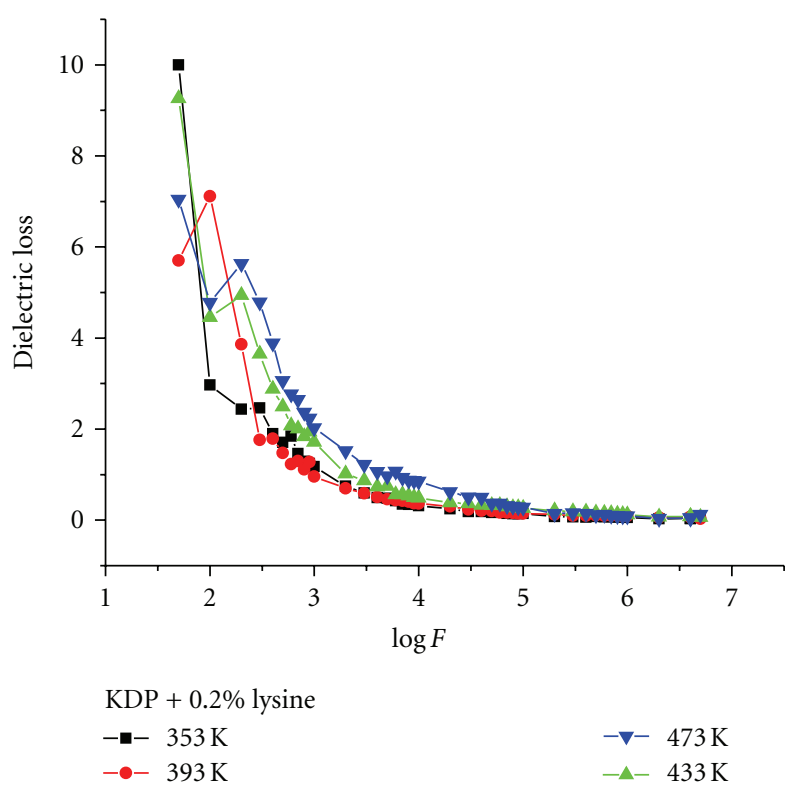

(b)

FIGURE 3: (a) variation of dielectric constant with frequency for all temperatures (lysine-doped KDP). (b) variation of dielectric loss with frequency for all temperatures (lysine-doped KDP).

heated or cooled [20]. The pyroelectric material shows change in the direction of spontaneous polarization when electric field is applied on them. Pyroelectric materials can be used as infrared and millimeter wavelength detector. The pyroelectric current measurement technique can be regarded as complementary to hysteresis loop measurement and applied to study of the Curie point transition.
From the dielectric study, we have shown the variation of current with temperature for $1 \mathrm{KHz}$ is shown in Figure 8, and it is found that current increases with temperature, and finally a critical temperature is reached above which pyroelectric current begins to decrease. For our KDP crystal, the critical temperature is found to be $120^{\circ} \mathrm{C}$ which closely agrees with the earlier literature [21]. Usually 

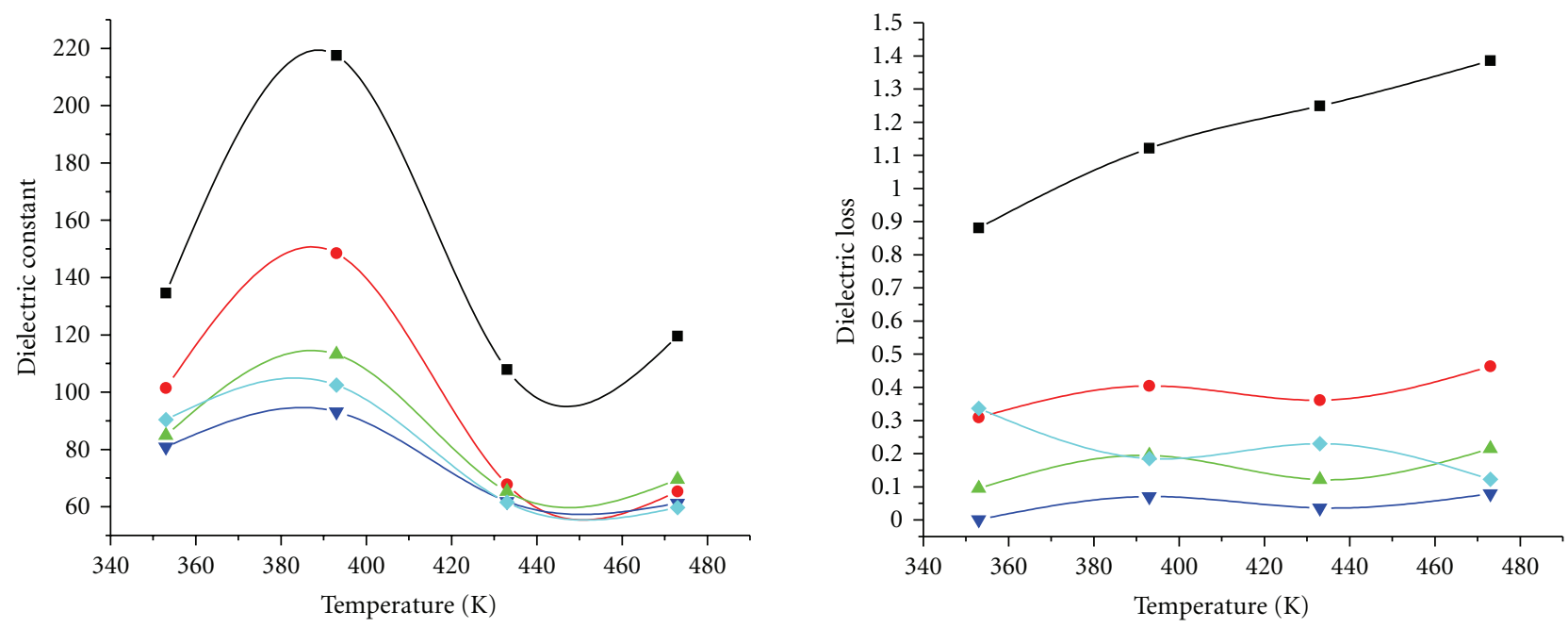

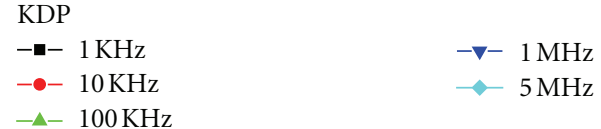

(a)

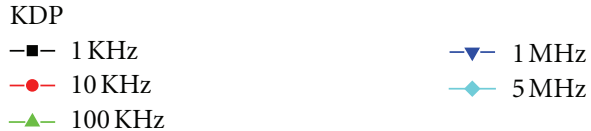

(b)

Figure 4: (a) Variation of dielectric constant with temperature for all frequencies (pure KDP). (b) Variation of dielectric loss with temperature for all frequencies (pure KDP).
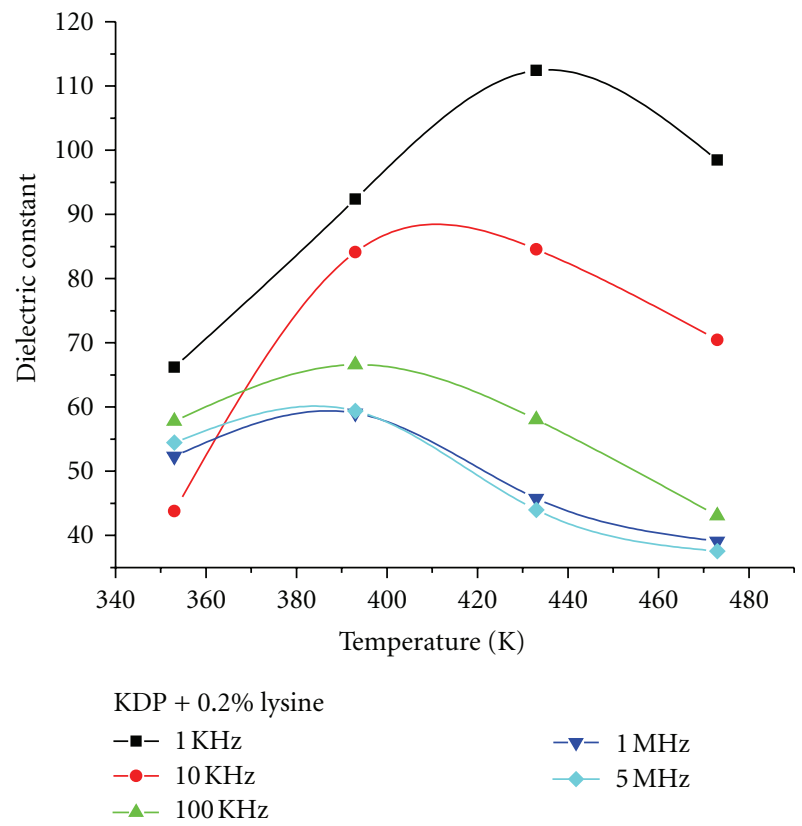

(a)
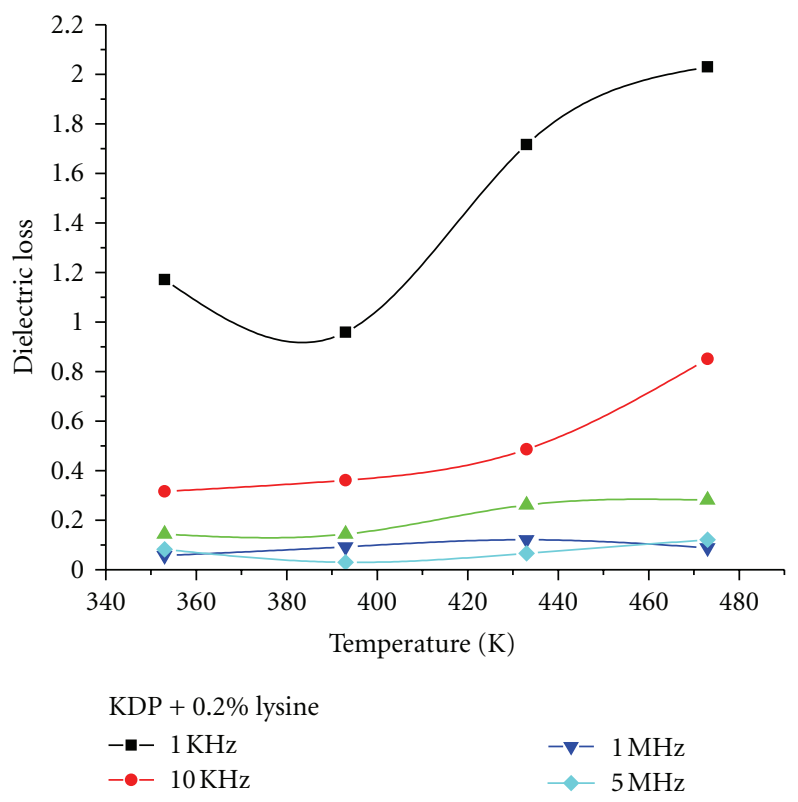

(b)

FIGURE 5: (a) variation of dielectric constant with temperature for all frequencies (lysine-doped KDP). (b) variation of dielectric loss with temperature for all frequencies (lysine-doped KDP).

higher temperature limit for the optical use of KDP crystals is set by their critical temperature, above which optical properties are affected and the crystal loses its transparency. Sometimes it may lead to cracking of the crystal.

\section{Conclusion}

Pure and lysine monohydrochloride-doped KDP crystals were grown by slow evaporation method. The UV-Vis spectra analysis reveals that the transmittance efficiency 

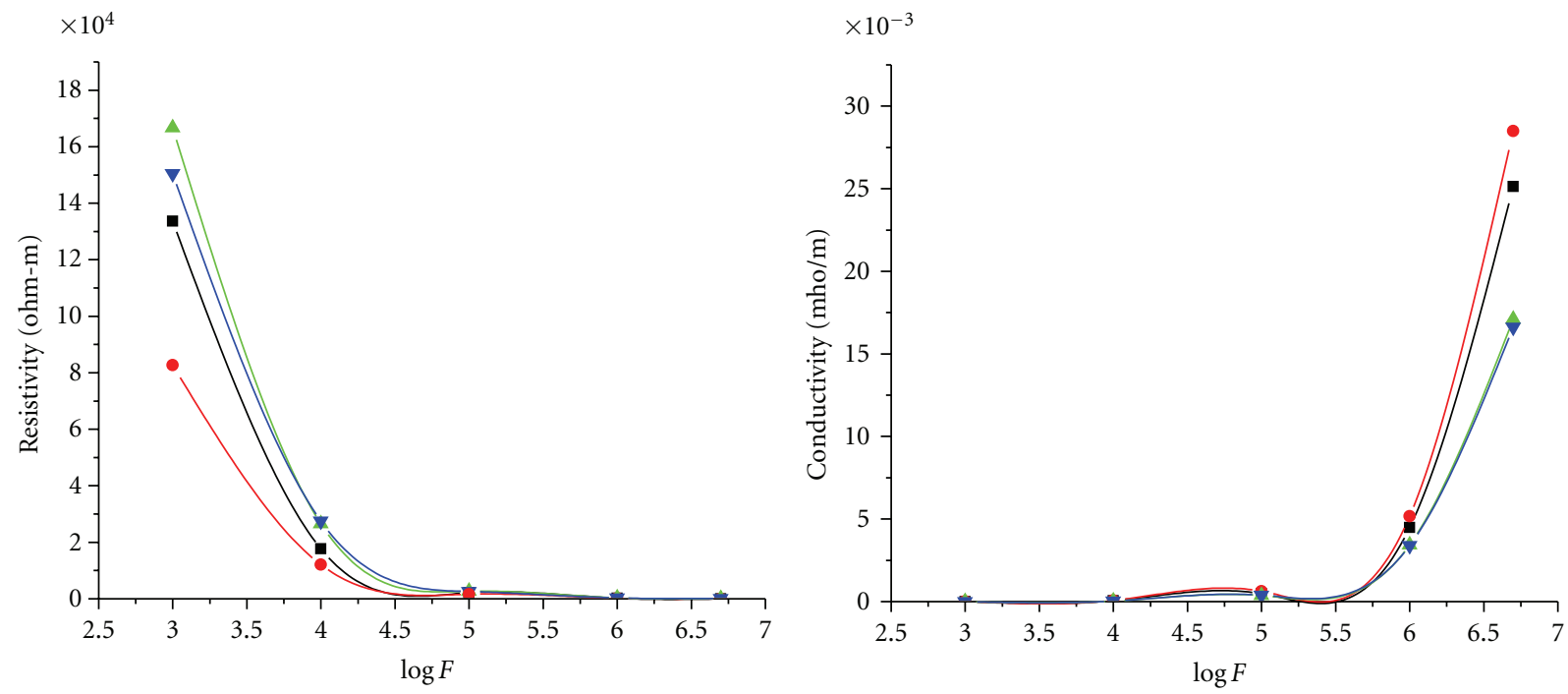

KDP

$-353 \mathrm{~K}$
$--393 \mathrm{~K}$

$-\nabla-473 \mathrm{~K}$
$--433 \mathrm{~K}$

KDP

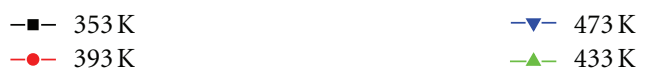

(b)

FIGURE 6: (a) Variation of resistivity with frequency (pure KDP). (b) Variation of conductivity with frequency (lysine-doped KDP).
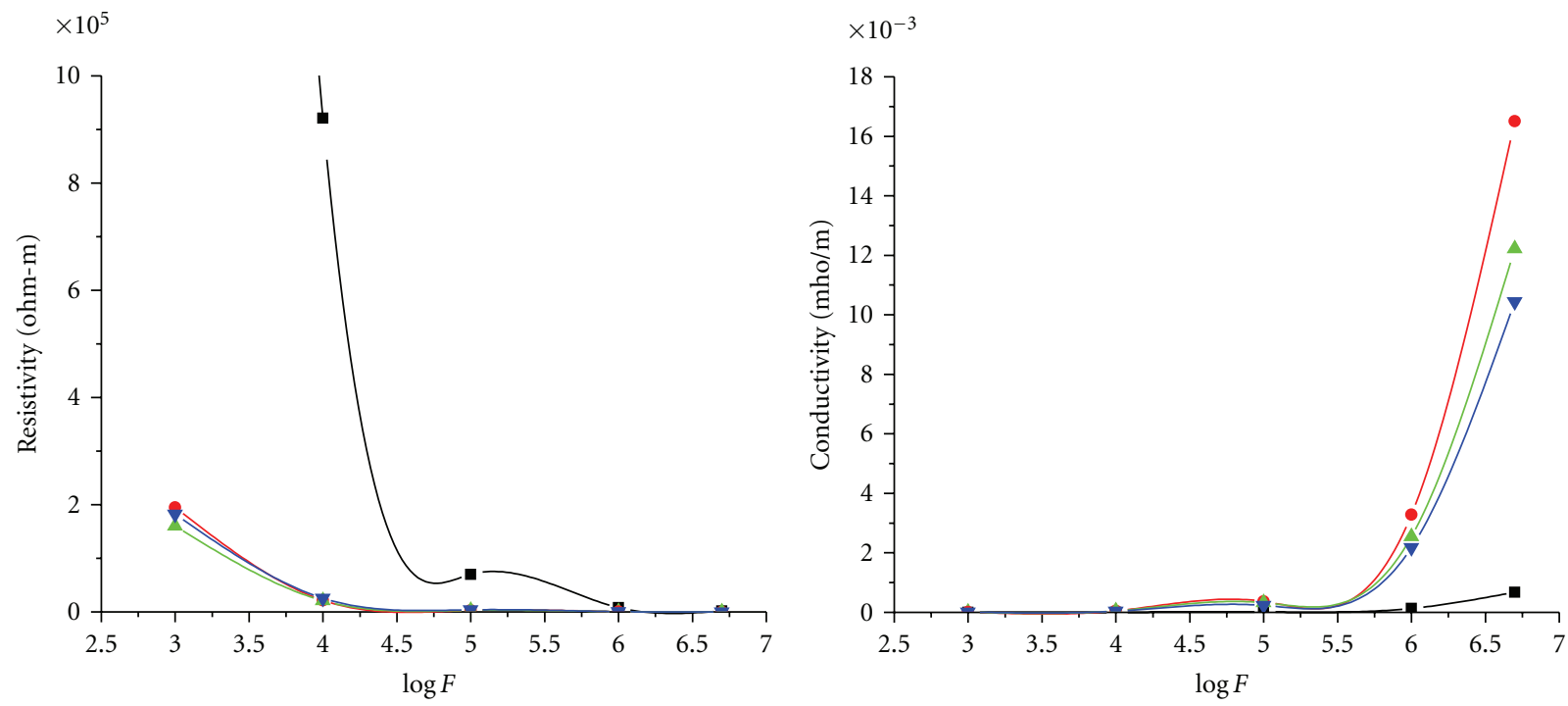

$\mathrm{KDP}+0.2 \%$ lysine
$--353 \mathrm{~K}$
$--393 \mathrm{~K}$

$-\nabla-473 \mathrm{~K}$

$-4-433 \mathrm{~K}$

(a)

$$
\begin{aligned}
& \mathrm{KDP}+0.2 \% \text { lysine } \\
& --353 \mathrm{~K} \\
& --393 \mathrm{~K}
\end{aligned}
$$

(b)

FIGURE 7: (a) Variation of resistivity with frequency (lysine-doped KDP). (b) Variation of conductivity with frequency (lysine-doped KDP).

improves considerably for the addition of lysine. The absence of absorption and excellent transmission in entire visible region makes this crystal a good candidate for optoelectronic application. Dielectric measurements indicate that the dielectric constant of both crystals decreases with increasing frequency significantly to make the crystal a more interesting material in the microelectronics industry. Also it is found that the dielectric constant and the dielectric loss of L-lysinedoped KDP crystals were lower than the pure KDP crystals. Also such kind of organic crystals possess extremely high sensitivity to the number of intrinsic defects. Hence L-lysinedoped KDP crystals are found to be more beneficial from an application point of view as compared to pure KDP crystals. 


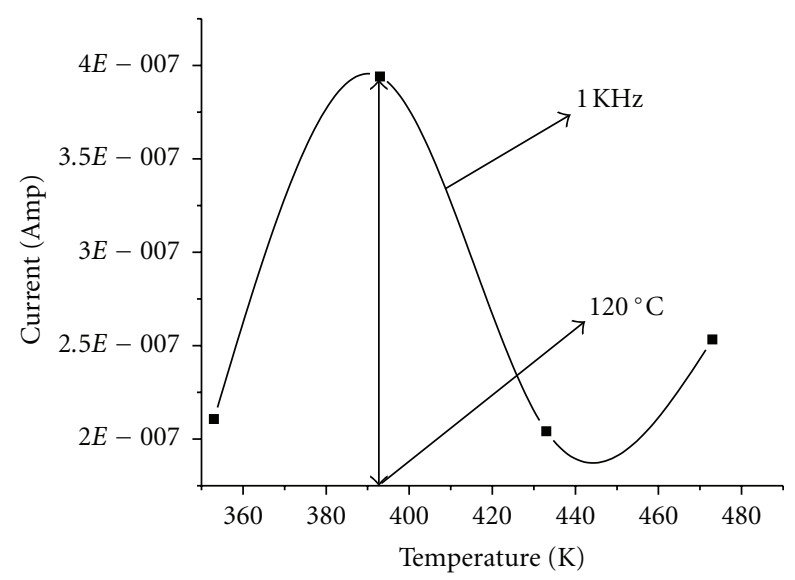

KDP

FIGURE 8: Variation in current with temperature.

\section{Acknowledgments}

Authors are highly thankful to Professor Vel. R. Rangarajan, Chairman, Vel Group of Institutions, Avadi, Chennai-62, and Dr. K. Siddappa Naidu, Principal, Vel Tech Multi Tech Dr. Rangarajan Dr. Sakunthala Engineering College, Avadi, Chennai-62, for their kind support and constant encouragement towards the authers' research work. Also one of the authors (N. Kanagathara) is highly thankful to HOD and all staff of Bio Technology Department, Vel Tech High Tech Engineering College, Chennai-62, Department of Physics, Loyola College for their kind support for providing lab facility.

\section{References}

[1] K. D. Parikh, D. J. Dave, B. B. Parekh, and M. J. Joshi, "Thermal, FT-IR and SHG efficiency studies of L-arginine doped KDP crystals," Bulletin of Materials Science, vol. 30, no. 2, pp. 105-112, 2007.

[2] K. D. Parikh, D. J. Dave, B. B. Parekh, and M. J. Joshi, "Growth and characterization of L-alanine doped KDP crystals," Crystal Research and Technology, vol. 45, no. 6, pp. 603-610, 2010.

[3] N. Vijayan, S. Rajasekaran, G. Bhagavannarayana et al., "Growth and characterization of nonlinear optical amino acid single crystal: L-Alanine," Crystal Growth and Design, vol. 6, no. 11, pp. 2441-2445, 2006.

[4] K. Ozga, V. Krishnakumar, I. V. Kityk, and J. Jasik-Ślezak, "l-lysine monohydrochloride dihydrate as novel elasto- and electrooptical materials," Materials Letters, vol. 62, no. 30, pp. 4597-4600, 2008.

[5] V. Krishnakumar, R. Nagalakshmi, S. Manohar et al., "Elastooptical spectra of novel L-lysine monohydrochloride dehydrate single crystals," International Journal of Modern Physics B, vol. 24, no. 5, pp. 629-645, 2010.

[6] P. V. Dhanaraj, N. P. Rajesh, P. Ramasamy, M. Jeyaprakasan, C. K. Mahadevan, and G. Bhagavannarayana, "Enhancement of stability of growth, structural and NLO properties of KDP crystals due to additive along with seed rotation," Crystal Research and Technology, vol. 44, no. 1, pp. 54-60, 2009.
[7] P. P. Kumar, V. Manivannan, P. Sagayaraj, and J. Madhavan, "Growth and characterization of pure and doped NLO Larginine acetate Single crystals," Bulletin of Materials Science, vol. 32, no. 4, pp. 431-435, 2009.

[8] B. S. Kumar and K. R. Babu, "Effect of L-arginine, L-histidine and glycine on the growth of KDP single crystals and their characterization," Indian Journal of Pure and Applied Physics, vol. 46, no. 2, pp. 123-126, 2008.

[9] A. Rahman and J. Podder, "Effect of EDTA on the growth kinetics and structural and optical properties of KDP crystal," International Journal of Optics, vol. 2010, Article ID 978763, 5 pages, 2010.

[10] V. Krishnakumar and R. Nagalakshmi, "Crystal growth and vibrational spectroscopic studies of the semiorganic nonlinear optical crystal-bisthiourea zinc chloride," Spectrochimica Acta A, vol. 61, no. 3, pp. 499-507, 2005.

[11] V. Venkataramanan, S. Maheswaran, J. N. Sherwood, and H. L. Bhat, "Crystal growth and physical characterization of the semiorganic bis(thiourea) cadmium chloride," Journal of Crystal Growth, vol. 179, no. 3-4, pp. 605-610, 1997.

[12] S. Boomadevi, H. P. Mittal, and R. Dhansekaran, "Synthesis, crystal growth and characterization of 3-methyl 4nitropyridine 1-oxide (POM) single crystals," Journal of Crystal Growth, vol. 261, no. 1, pp. 55-62, 2004.

[13] B. T. Hatton, K. Landskron, W. J. Hunks et al., "Materials chemistry for low-k materials," Materials Today, vol. 9, no. 3, pp. 22-31, 2006.

[14] S. Goma, C. M. Padma, and C. K. Mahadevan, "Dielectric parameters of KDP single crystals added with urea," Materials Letters, vol. 60, no. 29-30, pp. 3701-3705, 2006.

[15] S. Suresh, A. Ramanand, D. Jayaraman, and P. Mani, "Growth, photoconductivity and dielectric properties of triglycine sulfate (TGS) single crystals," Optoelectronics and Advanced Materials, vol. 4, no. 11, pp. 1763-1765, 2010.

[16] C. Balarew and R. Duhlew, "Application of the hard and soft acids and bases concept to explain to ligand coordination in double salt structures," Journal of Solid State Chemistry, vol. 55, no. 1, pp. 1-6, 1984.

[17] M. Meena and C. K. Mahadevan, "Growth and electrical characterization of L-arginine added KDP and ADP single crystals," Crystal Research and Technology, vol. 43, no. 2, pp. 166-172, 2008.

[18] S. Aruna, G. Bhagavannarayana, M. Palanisamy, P. C. Thomas, B. Varghese, and P. Sagayaraj, "Growth, morphological, mechanical and dielectric studies of semi organic NLO single crystal: 1-argininium perchlorate," Journal of Crystal Growth, vol. 300, no. 2, pp. 403-408, 2007.

[19] N. Pattanaboonmee, P. Ramasamy, R. Yimnirun, and P. Manyum, "A comparative study on pure, l-arginine and glycine doped ammonium dihydrogen orthophosphate single crystals grown by slow solvent evaporation and temperaturegradient method," Journal of Crystal Growth, 2010.

[20] J. G. WebsteR, The Measurement, Instrumentation and Sensors Handbook, CRC Press, New York, NY, USA, 1999.

[21] R. Mohite, "Rapid growth of KDP crystal by solution growth method with (EDTA, $\mathrm{KCl}$ ) additives and its characterization," International Journal of Computer Theory and Engineering, vol. 3, no. 2, 2011. 

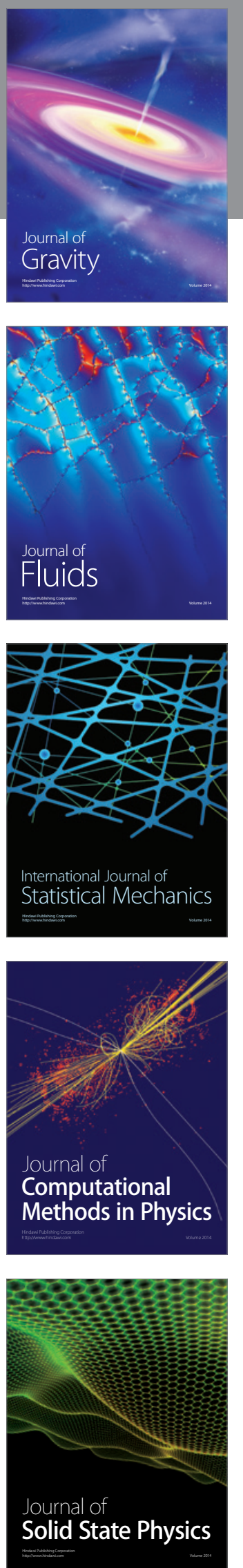

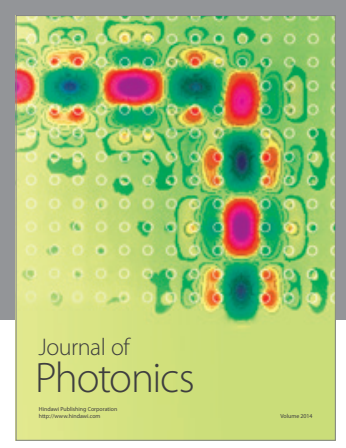

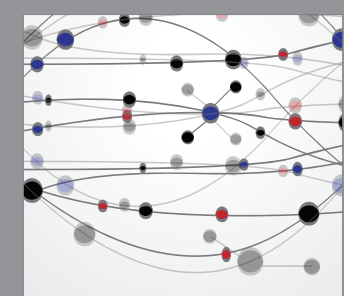

The Scientific World Journal
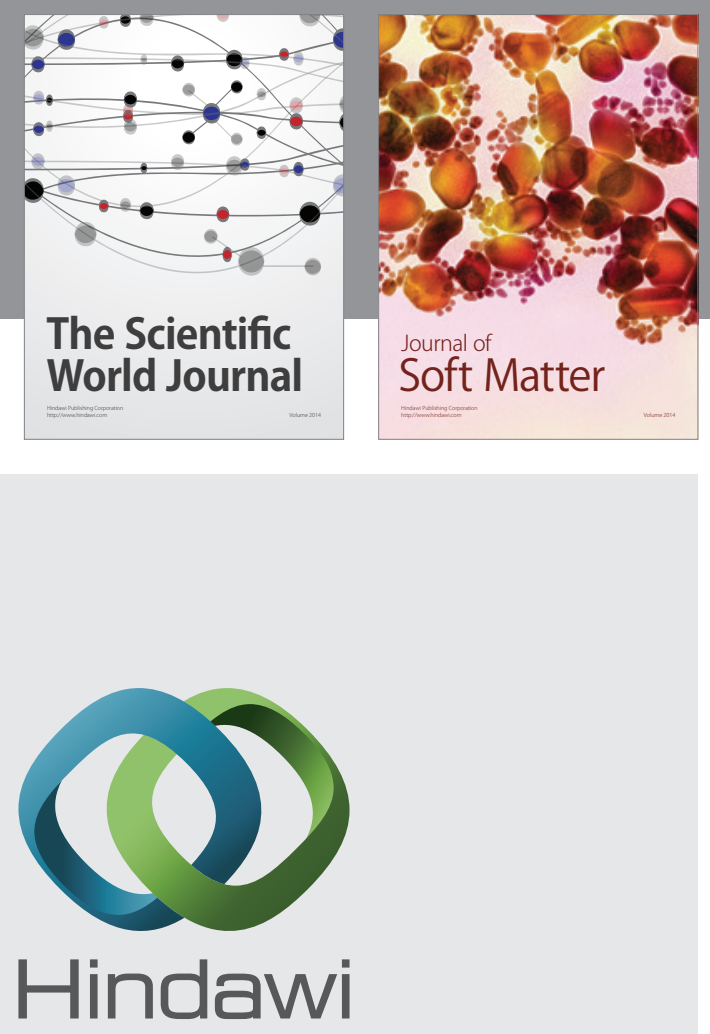

Submit your manuscripts at

http://www.hindawi.com
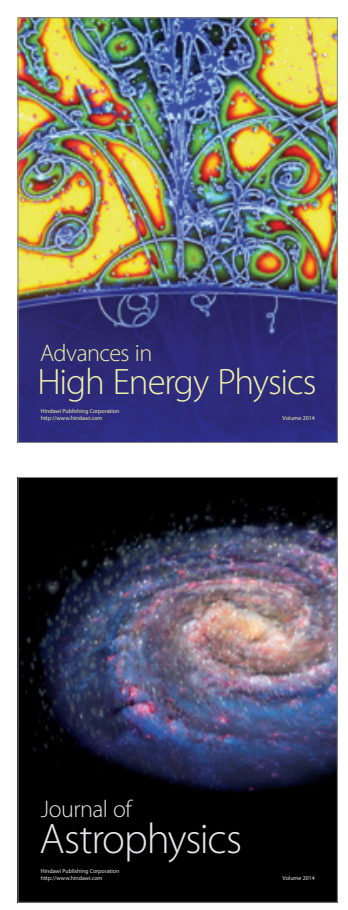
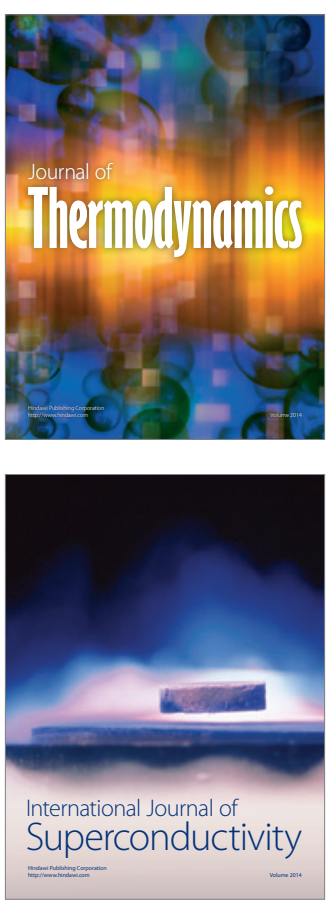
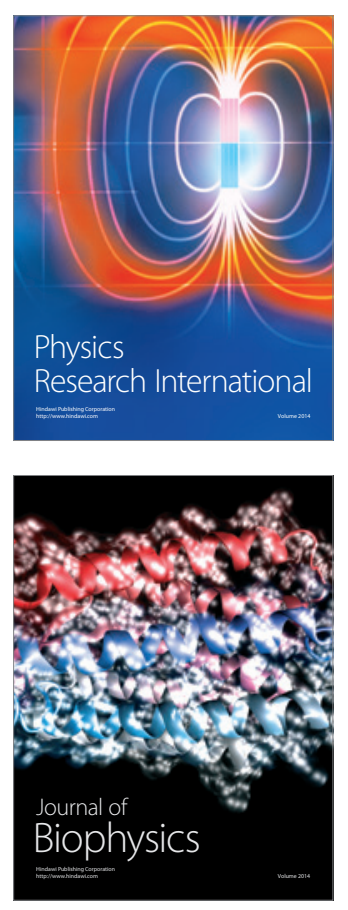
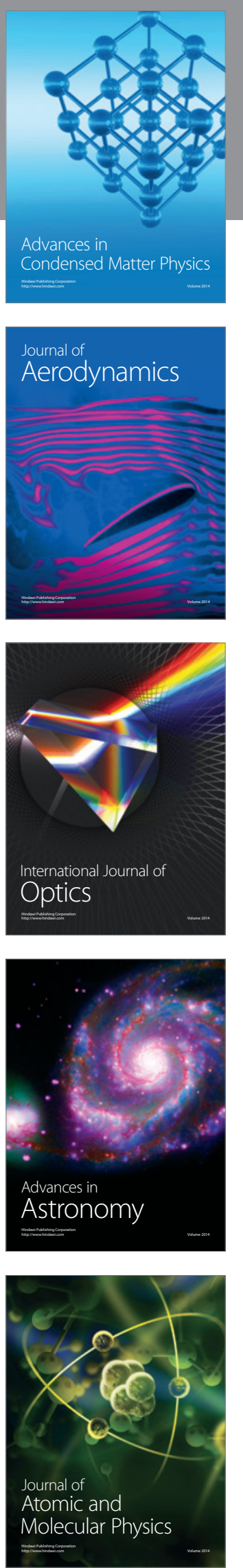